\title{
South Africans in flux: Exploring the mental health impact of migration on family life
}

\author{
M Marchetti-Mercer \\ Department of Psychology, University of Pretoria, Pretoria, South Africa
}

\begin{abstract}
In the context of post-apartheid South Africa mental health professionals are increasingly faced with the complexities linked to people leaving the country, those left behind and those returning. In an attempt to illustrate the mental health challenges linked to the South African migration phenomenon, this article will firstly explore the global phenomenon of migration and some of the theoretical approaches used to understand it. The psychological impact of immigration on individuals and their families will also be explored. In conclusion the author will propose some possible preventative measures which may be of use to mental health professionals.
\end{abstract}

Key words: South Africa; Mental health; Immigration and emigration, Family

Received: 10-01-2008

Accepted: 26-05-2008

\section{Introduction}

In the age of globalization societies have become more and more diverse and the phenomena of migration and exile have greatly transformed the fabric of many societies. In South Africa a very definite trend can be identified post - 1994 where a large number of South Africans have chosen to leave the country of their birth because of political and economic uncertainty as well as growing levels of crime and violence. ${ }^{1}$ Many young people tend to leave the country after completing their tertiary education and many South African families have been deeply affected as a result and find themselves with their children scattered all over the world. Mental health professionals may be increasingly faced with the complexities linked to the phenomenon of people leaving their country of origin and relocating to a foreign location. This is often referred to as a "brain drain" as many of the people leaving the country often have very specialized skills which are difficult to replace. Recently the South African government has engaged in an active "homecoming revolution", specifically targeting the 80000 to 1,2 million South Africans believed to be working in Britain. ${ }^{2}$ It may be important to note that this grouping of people returning home

\section{Correspondence:}

Prof Maria Marchetti-Mercer

Department of Psychology, University of Pretoria, Pretoria, 0001

email:maria.marchetti-mercer@up.ac.za after living abroad is likely to experience very specific adjustment problems linked to the relocation.

During the apartheid years South Africa also witnessed a process of emigration which was mostly because of political reasons and created a grouping of so-called exiles. ${ }^{3}$ This grouping of people was seen as quite different from the accepted understanding of exile, as it did not result in the aftermath of a war that was lost or a coup or revolution that failed. ${ }^{4}$ Many of the activists who left South Africa during these years regarded themselves as still very much part of the continuing and increasing struggle back home. This grouping of people was not homogenous as there were different streams of exile following certain politically explosive events such as Sharpeville in the sixties and the Soweto uprising in 1976.5 Furthermore most exiles left the country as individuals and were separated and often unable to make any contact with their families for a number of years.4 Many of this very specific grouping of people returned to South Africa in $1994 .{ }^{5}$

Returning to South Africa after many years was a challenging experience for the so called " exiles." Bernstein speaks of the "paradox of exile"4 when she describes the phenomenon that although "home" was the name they gave South Africa, the reality was that another foreign country had become "home." Not only did they find on their return that they had irrevocably changed, but that the South Africa they had left behind had also changed. Therefore many experienced a number of practical and psychological problems on their return. ${ }^{4}$ It may also have 
been that they did not receive the welcoming that they had expected; some of those left behind may have perceived exile as a "desertion" and this may have impacted negatively on relationship.s. ${ }^{4}$ Therefore those returning may have faced much criticism and resentment from those who had been left behind who had borne the brunt of waging the "struggle" from within South Africa.

It must be emphasised that moving from one's country of origin has become more prominent in the so-called age of globalisation as many people are able to move freely across boundaries and is not a phenomenon unique to South Africa. Migration must be seen as a relational phenomenon which affects a number of interconnected family systems. ${ }^{6}$ The people who leave the country of their birth are not the only ones affected but also those who stay behind. ${ }^{7}$ A number of psychological symptoms are known to be triggered or aggravated by the process of migration, for example depression, anxiety, pychosomatic illnesses, addictions or behavioural problems and these can be triggered at different times of the migration process or even at a much later stage. ${ }^{6}$ Other recent research has also looked at the link between migration and schizophrenia. ${ }^{3}$

\section{Perspectives on immigration}

In order to understand the psychological and sociological processes linked to the phenomenon of immigration a number of theoretical perspectives will be explored. Undergoing a process of assimilation and acculturation were often regarded as the best ways for people entering in a new country, although the difference between the two may be seen as subtle. ${ }^{8}$

LaFramboise et $\mathrm{ll}^{9}$ define these two as follows:

\section{Assimilation:}

This view postulates that a person entering a new culture needs to be absorbed into the dominant culture. Until this has taken place and he or she perceives an acceptance into the new culture, he or she will suffer from a sense of alienation and isolation. ${ }^{3}$ However this model, which appears to be the one that is more often than not advocated for successful integration into a new society, has not escaped criticism. For example DiNicola argues ,'In North America, those of us who have a complex personal identity are continually faced with questions about where we fit.... which challenges North American stereotypes of assimilation, which sets our implicit rules for dealing with such situations. This stereotype assumes that migrants and minorities are refugees of some sort, for political or economic reasons, who gratefully give up their attachments to other places and other ways of being ". 10

Some researchers such as Falicov ${ }^{11}$ also emphasise the fact that the necessity often placed on assimilation is more reflective of a certain ideology rather than an empirical inevitability. This may be more reflective of the receiving society's inability to tolerate difference.

\section{Acculturation:}

This view holds that through this process a person must become a competent participant in majority culture, but will always be identified as a member of the minority culture. This often is an involuntary process as a person has no choice but to follow this route, more often than not to survive economically. ${ }^{9}$ Bhugra points out that acculturation can be seen in terms of behaviour such as language, religion, entertainment, food and shopping habits. It may also include other areas such as cognitive style, behavioural patterns and attitudes. ${ }^{12}$ Until recently acculturation was seen as a good outcome for immigrants in a pluralistic society ${ }^{6}$ and it was believed that a rapid and successful process of acculturation could lead to better mental health ${ }^{13}$, while too much attachment to the country of origin was seen as an inability to adapt to the new culture. However recent research looking at the relationship between mental health and immigration indicates that attachment to one's old culture may in fact be beneficial. For example Vega ${ }^{14}$ argues that maintaining one's traditional culture may serve as a "buffer" to the negative mental health impact due to immigration. ${ }^{3}$ Therefore both concepts of accommodation and assimilation carry with them the assumption that the most adaptive way for a person entering a new society is to be absorbed into the dominant culture. This tends to be a non-critical perspective based on the notion that those views and values that hold the most power are necessarily the most desirable. However as has been pointed out above this may in fact not be preferable as far as people's mental health is concerned.

Recent literature explores the benefits of a process of transnationalism defined as, " living in one or more cultures and maintaining connections to both," (Stone et al ${ }^{15}$, p. 381) which might be linked to a Alternation model which tries to describe the process whereby it is possible for a person to know and understand two different cultures. ${ }^{9}$ This implies that old cultural meanings are retained while simultaneously new cultural modes are acquired. ${ }^{11}$ This way of being may be more relevant in the era of globalization where there may be a greater possibility to maintain this type of position as people lead a more transcontextual life. ${ }^{6}$ However, this may not always have been the case in the instance of immigrants at the beginning of the previous century as well as in the case of exiles and refugees. ${ }^{3}$ Stone et al also concur that this may have been more possible for immigrants coming to the US after 1965 as they have encountered a culture that is more accepting of multiculturalism. ${ }^{15}$ It may also be something experienced by South Africans leaving the country today.

\section{Phases of immigration}

The process of migration is likely to differ and not all individuals are likely to undergo the same experiences. ${ }^{12}$ It may also be that different generations may experience this differently. Sluzki ${ }^{16}$ has done some insightful work on migration and family conflict which will be further explored in the rest of the article so as to contextualise it for the present South African phenomenon. He identifies the following phases of the migration process: preparatory phase, act of migration, period of overcompensation, period of decompensation or crisis, transgenerational phenomena. Each phase is quite unique with regard to its characteristics as well as triggering various coping mechanisms on the part of the family and bringing about specific conflicts and symptoms. ${ }^{16}$

\section{Preparatory phase}

During this phase the family is committing itself to the process of leaving its country of origin. Migration can be seen either as something which is negatively motivated, for example in order to escape political oppression or high levels of crime; or alternatively positively motivated for example in order to make a 
better living. Bughra emphasises that it is important to recognise whether the move is voluntary or involuntary in order to assess its impact on the individual and his/her family. ${ }^{12}$ Those who migrate because of economic or educational improvement will experience different stresses than those of political exiles for example. People who have a high motivation to immigrate may experience less mental health problems than those who are reluctant to migrate. It may also be of interest to identify who is the motivator or 'responsible' for the decision to immigrate. Is the family moving because of a specific individual's career while the rest of the family is not privy to the decision? Is everyone in the family equally committed to the decision to immigrate? This may be a time of very mixed feelings, euphoria at the excitement of the move together with feelings of sadness, uncertainty and fear at what lies ahead.

\section{The act of migration}

Many of our important developmental tasks are linked to very specific rituals. However there are very few or no prescribed rituals attached to the act of migration. ${ }^{16}$ It is more often than not a leap in the dark and every family's experience may vary quite dramatically. Each family may also approach this process differently. Some families may approach migration as something quite final and almost burn their bridges. Others may leave telling everyone that they are going only for a while, this may be the case with many South Africans who leave after University in order to make some money to pay off study loans. Some families explore the country of destination first, perhaps by visiting it first or sending some members almost as "scouts' before the rest of the family also goes. Some families are able to migrate legally and go through all the legal processes while others do so illegally. Of course in the final analysis some choose to migrate while others are forced to do so and this may also play an important role on the process.

\section{Period of overcompensation}

Sluzki is of the opinion that what he calls "migratory" stress does not take its toll on the family in immediate weeks or even months following the migration process. ${ }^{16}$ At this stage the family is completely focused on adaptation and survival and members of the family might in fact be quite unaware of the stressful nature of the migration as well as its impact on the family life.

During this period the family is also confronted more often than not with a cultural context which is very different from its own. However because the need to survive is so great often families experience what can be viewed as a relative moratorium with regard to acculturation and accommodation. ${ }^{16}$ In other words many of the conflicts that may be experienced in terms of being faced with a culture that is quite alien from one's own remain almost dormant. Family features that were characteristic prior to immigration may become almost exaggerated for example families that were close may become even closer or families that were distant may become even more autonomous. ${ }^{16}$

One of the characteristics of this kind of moratorium is the collective myth that after a period of time the family may be able to return to the country of origin. ${ }^{16}$ This kind of thinking may lead to families clinging to the norms of their country of origin and not really engaging with their new cultural environment. However this strategy cannot last ad infinitum and it may, after a period of some months, lead to a major crisis, which will be discussed next.

\section{Period of decompensation or crisis}

This is a period which is potentially ridden with difficulties and conflicts and certain symptoms may be displayed in the family. ${ }^{16}$ During this period the main task of the family becomes that of reshaping its identity. It has to find a balance between its old identity, which is linked to its country of origin and the new environment to which it has migrated. Finding a balance might be very tricky and there might be a difference in adaptation between adults and children. This important difference will be explored in more detail later in this article.

In general the family may have to be forced to change its rules of behaviour. What worked and was acceptable in the country of origin may no longer be relevant in the country of destination. These differences are often again highlighted by the behaviour of children who often adapt much more quickly to the new country. It is during this period that the strengths and weaknesses of the family's coping skills are likely to be highlighted ${ }^{16}$ as well being cumulative and will come to expression in the months and sometimes the years after migration.

It may also be during this period that gender roles become highlighted and the difference between men and women may become even more marked. Hynie ${ }^{17}$ points out that the power relationship between members of a couple are to be measured in two ways namely the patterns of decision- making as well as the division of household tasks. More often than not women, even those who did not work in their country of origin have to work in the new country but this does not translate into an equal division of household tasks by both men and women. An added issue for South African families might be that in their country of origin they were used to full-time or at least part-time domestic help while they find themselves now having to take on the added burden of carrying domestic responsibilities as well as having to negotiate a new work division around these. This can become a potential source of conflict as well as taking up a lot of time of energy in the family.

The importance of the accepted cultural norms and roles that people bring with them in a new country cannot be overemphasised. An interesting longitudinal study was undertaken by Noh et al examining the depression rates of factors related to depression among Korean women immigrants in Toronto, Canada. ${ }^{18}$ The results showed that those women who were employed were almost eight times as likely to exhibit depression. Generally research has supported the fact that mental health might be positively connected to employment (for example Gore \& Mangione ${ }^{19}$ ). However in this instance it may have been because of the traditional roles and gender expectations of that particular culture (Korean) which mainly defines women as homemakers and mothers. Therefore being employed may in fact have been stressful as it came in direct conflict with their traditional cultural norms and these women may have been experiencing a double burden. Other researchers have also found similar tendencies of higher mental problems amongst women immigrants. ${ }^{20}$

Gender differences in adaptation may have also been reflected in the older generations of immigrants. It may have been more likely that the man dealt a lot with what can be termed "instrumental activities" 16 which involved much more of a connection with the new country while the woman may have been more responsible for maintaining links with the country of origin through correspondence and so forth. The danger of this 
may have been that in this very rigidly defined role distribution one member of the couple may have ended up adapting more quickly to the new country while the other one, usually the woman, was left more isolated and involved in a never ending process of mourning for what has been left behind. In both instances the experience of immigration may have left the woman feeling more vulnerable.

Therefore all these factors must be taken into consideration when looking at the experiences of couples in this phase. Another factor which may also have an impact is the educational level and occupational background of the people involved. If people have to do what they consider to be menial work for which they may be totally overqualified this may seriously impact their self-esteem. ${ }^{12}$

Families either emerge from this phase as having integrated the old and the new successfully and emerge with new individual and collective strengths or alternatively you get a situation where what has been left behind becomes more and more idealised which of course then makes adaptation much more difficult. ${ }^{16}$ Alternatively when everything that belongs to the country of origin becomes denigrated this may make the process of mourning and working through the loss more difficult. It may also be problematic if different members of family have very different experiences around this process. ${ }^{\text {? }}$

\section{Transgenerational phenomena}

It is in the context of the family that norms and rules regarding culture are often transferred so any problems that are not addressed by the family that initially immigrates may only become apparent in the second generation (namely the children raised in the country of adoption). This may be seen in the form of a clash between generations. ${ }^{16}$

This highlights once again that the phenomenon of immigration is not a homogenous one and, even within the context of a specific family, may be experienced quite differently. ${ }^{3}$ It is especially important to be sensitive to the experience of children in this process. Marchetti-Mercer and Louw argue that it may be easy to believe that children do not experience the same difficulties as adults given that they may be less attached to their larger community represented by the country of origin but rather to their family context. ${ }^{3}$ However in most instances children are not consulted in the decision to immigrate and moreover they are very dependent on the adults in their lives who may be experiencing great stress and therefore be unable to provide the security and support needed. ${ }^{21}$ The needs and stressors of the adults often take precedence, while children may often be ignored in this process.

Certain stressors may also be linked to specific developmental phases. Adolescent are particularly at risk as peers and peer acceptance are highly valued. "Fitting in" and "belonging" are two very important needs experienced by adolescents. Consequently having to enter a new school system feeling different, while often not being able to speak the local language and not understanding the accepted ways of behaving may be very traumatic for an adolescent. ${ }^{3}$ Grinberg and Grinberg argue that often in this period the effects of migration will be mostly seen in the school environment where the youth has to find and carve out a place for himself or herself. ${ }^{21}$ If children come from a culture which is more collectivistic, where group harmony, obedience and hierarchical relationships are valued over and over individual needs, and the country of origin has a more individualistic approach, the potential for intergenerational conflict is even higher as the children absorb the new values especially in the school and peer context. ${ }^{17}$

Families may be faced with the dilemma that they may want to encourage their children to acculturate quickly as this may lead to more success (for example academic performance, successful peer relationships, quick acquisition of the new language) while knowing that by acquiring the new culture this will mean loss of the original culture (for example loss of the mother tongue). ${ }^{17}$ The potential for conflict may be even higher during the period of adolescence where the potential for conflict between parents and children is already high.

In general children may become frustrated with the parents' lack of knowledge of the new culture, and may feel that they are in fact better able to navigate the new culture than their parents. This may lead to a situation where children feel that parents cannot provide them with adequate role modelling and may lead to further conflict and further alienation between the two. ${ }^{17}$ Stone et $\mathrm{l}^{15}$ however argue that in a family system where "transnationalism" is embraced the possibility of conflict between the two generations may be reduced. Children may regard their parents as "worthy carriers" of cultural knowledge from the country of origin. This might eliminate the conflict between those who are stuck in the past (the parents) and those who have adapted to the present (the children).

As far as older people are concerned the process of migration also holds certain problems. ${ }^{21}$ In many cases they do not wish to move and may do so only to follow their adult children on whom they are reliant for physical and psychological care. In this process they are likely to lose more than what they might gain. ${ }^{21}$ An added concern may be that this may make them totally dependent on their children as they find themselves in a strange new country with no other social connections. This alienation may be acerbated if they do not speak the language of the country of destination.

Another very real problem, which is facing many families in South Africa, is that of elderly parents being left behind when their children emigrate. This is likely to become an increasing socio-psychological reality as elderly people find themselves facing their latter years without the presence and support of their children and grandchildren.

\section{The role of language in the process of migration}

Language provides the basis for one's identity and plays a very important role in the lives of people entering a new country. ${ }^{21}$ Although in most of the countries where South Africans tend to immigrate such as the U.K., Australia, New Zealand and Canada, English is spoken there may be peculiarities of vocabulary or accent, which further add to the complexity of experience. Many South Africans emigrating are also not mother tongue English speakers and they may find themselves having to communicate in a language in which they do not feel fully comfortable.

One's own language, the mother tongue, is never as completely invested as when one lives in a country where a different language is spoken. All childhood experiences, memories, and feelings about early object elations are connected to language. Special meanings become embedded in it. ${ }^{21}$ Schaff ${ }^{22}$ considers it one of the most traditional elements of culture, as well as the one which is the 
most resistant to change. ${ }^{3}$

One could compare having to learn the language of a new country to the experience of a child entering the world. An immigrant's inability to speak the local language properly or with an accent may add to a sense of inferiority and incompetence and may prove to be a source of anxiety. ${ }^{3}$ It has been shown that children tend to acquire a new language more quickly, firstly because they are more receptive but also because they don't want to be perceived differently by their peers. ${ }^{22}$ As children become more proficient in the language of the new country they may also become less interested in retaining their mother tongue which may also bring about conflict between them and their parents. Furthermore the family may find itself in a situation where the children being more proficient in the new language are more comfortable negotiating the outside world and parents become dependent on their children for communicating with the outside world. ${ }^{3}$ This may bring about a shift in the power balance in the family which may be problematic especially in fairly traditional cultures.

\section{Preventative measures for families planning to immigrate}

It is absolutely essential that families planning to immigrate prepare themselves and mental health professionals may aid them in this process via the following strategies:

1. Preparing the family that there will be periods of loneliness and felling uprooted, but that this is a fairly common experience and should not be labelled negatively.

2. Emphasising the importance of remaining in contact with people from the country of origin. In today's high-tech world this is made easier by the availability of e-mail and low cost telephone services making daily communication more accessible.

3. If the country to which the family is immigrating has a different language encouraging them to learn as much of it as possible.

4. Emphasising the importance of learning as such as possible about the practicalities of the country of destination, and the more subtle social rules.

5. Ensuring that the family maintain a level of continuity with the physical environment they are leaving behind by encouraging them to bringing together some meaningful objects such as photos and momentos. ${ }^{16}$

It also essential that the couple prepare themselves and discuss issues around financial and household responsibilities so that they both clearly understand what are the expectations once they have immigrated, for example will they both work, how will the money earned be allocated, who will be responsible for which household tasks, who will take over which responsibility as far as the children are concerned. There should also be a thorough discussion with all members of the family especially the children, who more often than not are not part of the decision to immigrate. It is important to prepare them and allow them the opportunity to remain connected to their friends and other family members in the country they are about to leave.

It is also important to include those members of the family that are to be left behind for example grandparents, other brothers and sisters. All members of the family should have clarity on how contact will be maintained for example telephonically, through electronic mail and how often visits may happen. The impact of the immigration on those left behind should not be ignored nor underestimated and the trauma associated with this loss must be carefully taken into consideration. This group may experience serious feelings of abandonment and even anger and resentment towards those who are leaving. As discussed earlier elderly people may have to face the reality of old age without the presence and support of their children and grandchildren. This may hold very real practical problems and dilemmas which need to be discussed and resolved before the departure of the other family members.

A few words regarding those returning to South Africa after a period of time may also be of relevance. It may in fact be that this return may hold the same challenges as the original migration and that those returning may face similar personal and family crises. ${ }^{21}$ Returning South Africans may in fact find themselves as foreigners in their country of origin in the same way as those exiles returning after the dismantling of apartheid. From a mental health perspective it is therefore important to be sensitive and proactive towards the psychological stressors these people may experience.

Given the risk factors that have also been identified regarding mental health and immigration, mental health professionals should also assess possible vulnerable individuals and families and prepare them adequately for the migration process. In addition people may fear the stigma attached to psychiatric diagnosis when applying for entry into a new country and may also be loathe to continue with their medication. Situations may even arise where people request that their diagnoses be altered or deleted placing psychiatrists and psychologists in very real ethical dilemmas. All these issues may need to be very carefully negotiated so that the therapeutic process is not compromised.

Lastly it must be remembered that mental health professionals working with emigrants are themselves part of the group of people "left behind." More and more professionals are leaving the country and those still living and working in South Africa may also experience feelings of ambivalence, which may be evoked when working with these specific clients or patients. It is important that they be aware of their own subjective feelings and the impact these may have on the therapeutic relationship.

\section{Conclusion}

This article has attempted to show that immigration is a complex psychological and socio-cultural phenomenon which permeates present South African society and is having an enormous impact on the family life of many people. More and more mental health professionals are encountering people who choose to leave the country as well as those who have to deal with the aftermath of this decision. It is therefore necessary to take cognisance of the process that people undergo when they leave their country of origin as well as helping them develop adequate strategies to cope with the stresses associated with it.

\section{Acknowledgement}

The material is based upon work supported by the National Research Foundation (NRF). Any opinion, findings and conclusions or recommendations expressed in this material are those of the author and therefore the NRF does not accept liability in regard thereto. 


\section{References}

1. Goldin J. Belonging to two worlds: The experience of migration. South African Psychiatry Review. 2002 November: 4-6.

2. The home coming revolution In Star Newspaper, October 312007

3. Marchetti-Mercer MC, Roos L. Migration and exile-some implications for mental health in post-apartheid South Africa. South African Journal of Psychiatry 2006; 12(3):52-64.

4. Bernstein H. The rift: The exile experience of South Africans. London: Jonathan Cape; 1994.

5. Marchetti-Mercer MC. Towards new conceptualisations of the concept of home. Acta Academica 2006; 38(2):191-218.

6. Falicov CJ. Working with Transnational Immigrants: Expanding meanings of family, community and culture. Family Process 2007; 46(2) 157-171.

7. Falicov CJ. Emotional transnationalism and family identities. Family Process 2005; 44(4): 399-406.

8. Gordon MM. Assimilation in American Life. NY,USA: O.U.P. ; 1964

9. LaFramboise T, Coleman HL, Gerton J. Psychological impact of biculturalism: evidence and theory. Psychological Bulletin 1993; 114(3): 395-412.

10. DiNicola V. A stranger in the family. New York: W.W.Norton \& Co.;1997.

11. Falicov CJ. Latino Families in therapy: A guide to multicultural practice.New York: Guilford Press; 1998

12. Bughra D. Migration and mental health. Acta Psychiatrica Scandinavia 2004; 109: 243-258.
13. Escobar JL. Immigration and mental health. Archives of General Psychiatry 1998; 55(Sep): 781-782.

14. Vega WA. Lifetime prevalence of DSM IIIR psychiatric disorders among urban and Mexican Americans in California. Archives General Psychiatry 1998; 15: 771-778.

15. Stone E, Gomez E, Hotzoglou, D, \& Lipnitaky, J. (2005) Transnationalism as a motif in Family Stories. Family Process 2005; 44(4): 381-398.

16. Sluzki C. Migration and family conflict. Family Process 1979; 18: 379-390.

17. Hynie, M. From conflict to compromise: Immigrant families and the processes of acculturation In: Taylor DM, ed, Diversity with justice and harmony: A social psychological analysis. Ottawa: Canada: Department of citizenship and Immigration; 2006. p 97-123.

18. Noh SH, Wu Z, Speechley M, Kaspar V. Depression in Korean immigrants in Canada: II. Correlates of gender, work and marriage. Journal of Nervous and Mental disease 1992; 180: 578-582.

19. Gore S, Mangione TW. Social roles, sex roles, ad psychological distress: Additive and interactive models of sex difference. Journal of Health and Social Behaviour 1983; 24: 300-312.

20. Bughra, D, Leff J, Mallett R, Corrdan B, Rudge S. Incidence and outcome of schizophrenia in Whites, African Carribeans and Asians in London. Psychological Medicine 1979; 27: 791-798.

21. Grinberg L, Grinberg R. Psychoanalytic perspectives on migration and exile. New Haven: Yale University Press; 1989.

22. Schaff In Grinberg L, Grinberg, R. Psychoanalytic perspectives on migration and exile. New Haven: Yale University Press; 1989. 